Motrivivência $\quad$ v. 26, n. $42, \quad$ p. 175-184, junho/2014

http://dx.doi.org/10.5007/2175-8042.2014v26n42p175

\title{
PROPOSTA CURRICULAR DE SANTA CATARINA E A FORMAÇÃO CONTINUADA NA GERED DE CRICIÚMA/SC: a continuidade da descontinuidade
}

\author{
Vidalcir Ortigara? \\ Matheus Bernardo Silva² \\ Vônia Vitório ${ }^{3}$
}

\section{RESUMO}

Esse artigo tem como enfoque observar os cursos de formação continuada realizadas durante os anos 2003 a 2010 na 21ª GERED situada no município de Criciúma/SC. Partimos como ponto de análise para estas formações os pressupostos da Proposta Curricular de Santa Catarina, juntamente com outros documentos efetivados a posteriori da mesma. A questão metodológica se caracterizou como uma análise documental das formações realizadas. Verifica-se que no período analisado ocorreram "cursos" que se encaixariam como formações continuada, entretanto, esses cursos foram realizados de forma fragmentada e desarticulada entre os mesmos, resultando, portanto, em uma ineficácia de um processo que realmente alicerce os docentes em suas ações mediante os elementos norteadores contidos na Proposta Curricular.

Palavras-chave: Proposta Curricular de Santa Catarina; Formação Continuada; Educação; Educação Física.

1 Doutor em Educação. Docente do Programa de Pós-Graduação em Educação da Universidade do Extremo Sul Catarinense. Criciúma/Santa Catarina, Brasil.

E-mail: vdo@unesc.net

2 Mestre em Educação pela UFPR. Curitiba/Paraná, Brasil.

E-mail: matheusbernardo25@gmail.com

3 Mestre em Educação pela UNESC. Docente no Curso de Educação Física da UNESC.Criciúma/Santa Catarina, Brasil. E-mail: vvi@unesc.net 


\section{CONSIDERAÇÕES INICIAIS}

O presente estudo tem como objetivo apresentar um recorte do projeto de pesquisa intitulado "Proposta Curricular de Santa Catarina e Formação Continuada: um processo articulado?". O enfoque dado será com base na pesquisa feita na $21^{\text {a }}$ Gerência Regional de Educação - GERED - situada no município de Criciúma ${ }^{4}$, Santa Catarina, Brasil. Essa GERED abrange a região dos municípios que constituem a Região Carbonífera Catarinense e se articulam por meio de uma associação de municípios denominada AMREC - Associação dos Municípios da Região Carbonífera ${ }^{5}$ - abrigando 182 professores de educação física, inseridos em 62 escolas $^{6}$.

A pesquisa se efetiva no levantamento realizado das formações continuada que ocorreram na $21^{\text {a }}$ GERED. Busca analisar os dados quantitativos e qualitativos das formações realizadas durante os anos de 2003 a 2010. O material para análise foi acessado via $21^{\text {a }}$ GERED, que forneceu os mesmos na sua forma impressa e digital. Contudo, partimos como ponto de análise dessas formações a própria Proposta Curricular de Santa Catarina (1991), juntamente com outros documentos ${ }^{7}$ efetivados a posteriori da mesma.
A guisa de metodologia efetivou-se no primeiro momento, o envio a GERED um ofício, com intuito de explicitar a pesquisa e solicitar para que a gerência enviasse para o nosso acesso dados sobre os docentes e suas formações. Em posse dos documentos da GERED de Criciúma foi realizada a descrição qualitativa e quantitativa dos mesmos. Esta envolveu a leitura dos documentos buscando observar se ocorreram formações continuada para os docentes de educação física de modo geral e específico da área.

Apoiamo-nos em Triviños (2009) para fundamentar a questão metodológica que se caracteriza como uma análise documental que é um tipo de estudo descritivo que fornece a possibilidade de reunir uma grande quantidade de informações sobre um assunto, que leva a compreensão dos fatos e fenômenos de determinada realidade.

Para a análise dos documentos, o referencial teórico utilizado se fundamentou na perspectiva histórico-cultural que pauta os pressupostos teórico-metodológicos da Proposta Curricular (1991), nos conceitos de formação continuada e nas bases epistemológicas da educação e da educação física.

A Proposta Curricular (1991), por vez, é - nos últimos vinte e três anos - o principal documento norteador das ações

4 O município de Criciúma localiza-se na região do extremo sul catarinense. Sendo o município polo da região sul catarinense se constituindo o maior município entre Florianópolis e Porto Alegre. Criciúma possui uma população estimada em cento e noventa mil pessoas.

5 Os municípios que compõem a AMREC são: Cocal do Sul, Criciúma, Forquilhinha, Içara, Lauro Muller, Morro da Fumaça, Nova Veneza, Orleans, Siderópolis, Treviso e Urussanga. A população compreendida nesses municípios é de aproximadamente trezentos e noventa mil pessoas.

6 Dados obtidos na GERED de Criciúma no dia 07 de agosto de 2012.

7 A Proposta Curricular é composta pelos seguintes Documentos: Proposta Curricular: uma contribuição para a escola pública do Pré-Escolar, $1^{\circ}$ grau, $2^{\circ}$ grau e Educação de Adultos (1991); Proposta Curricular de Santa Catarina: Educação Infantil, Ensino Fundamental e Médio: Disciplinas curriculares (1998); Proposta Curricular de Santa Catarina: Educação Infantil, Ensino Fundamental e Médio: Formação docente para educação infantil e séries iniciais (1998) Proposta Curricular de Santa Catarina: Estudos Temáticos (2005). 
pedagógicas nas escolas estaduais de Santa Catarina. Objetiva propulsar nas escolas diretrizes, orientações para a intervenção pedagógica. Portanto, todas as escolas estaduais devem - ou ao menos deveriam - seguir os pressupostos teóricos e práticos da Proposta Curricular.

Dessa maneira, apresentaremos posteriormente a necessidade do debate entorno da Proposta Curricular (1991) vinculado com os processos de formação continuada - se é que eles existem - para os docentes e, no segundo momento explicitaremos os resultados obtidos com a pesquisa.

\section{Proposta curricular e formação continuada: uma ação necessária}

Está instalado no meio acadêmico e científico o debate sobre a qualidade educacional das escolas públicas. Nesse debate, em especial no pedagógico, verificam-se adesões e apropriações de teorias e autores com análise superficial da coerência e abrangência de seus discursos, o que acarreta proposições e sugestões conflitantes com o próprio discurso que as fundamentam. Parte-se da posição de que para a proposição pedagógica necessita-se ter o domínio teórico e operacional do projeto que se propõe.

Em vários estados e municípios, por iniciativa das Secretarias da Educação, formularam-se nas últimas décadas propostas pedagógicas-curriculares com o intuito de orientar a prática pedagógica dos docentes. Geralmente, como ocorreu no Estado de Santa Catarina, esse processo contou com a participação dos professores ${ }^{8}$. Porém, estudos têm demonstrado que após duas décadas de debates ainda não se alcançaram resultados satisfatórios em termos da qualidade educacional apontada nos Documentos de que a atividade educativa será mais

consequente em relação aos objetivos políticos pedagógicos, quando os professores, como intelectuais, desenvolverem na sua prática de vida e de trabaIho, as relações sociais reais que estão por trás das tendências, das técnicas, dos discursos, dos programas de ensino e por aí, dar uma dimensão política a sua prática pedagógica" (PROPOSTA CURRICULAR 1991, p. 69).

Os discursos oficiais ressaltam a responsabilidade dos professores nesse processo e defendem a importância da formação continuada como um dos mecanismos que conduziriam à "qualidade" almejada (AVILA; ORTIGARA, 2007). Embora consideremos que os problemas em qualidade da educação pública vão muito além da responsabilidade do corpo docente, partilhamos do pensamento de que os professores são o elo principal no processo de condução da atividade pedagógica desenvolvida nas escolas. Também consideramos que as proposições pedagógicas formuladas por estados e municípios, ainda que necessitem de ajustes, podem

8 Embora tal participação tenha sido restrita, ou pelo número de participantes ou pelas possibilidades de conciliarem essa participação com suas atividades cotidianas, as proposições tornaram-se um dos elementos de orientação das atividades. Ressaltamos que eles não são produtos isentos das contradições constantes nas relações de forças políticas neles envolvidas. 
ser importantes mecanismos no processo de estabelecer os rumos desta atividade. Como propositores, os órgãos governamentais também proporcionam aos seus professores formação continuada com o intuito de auxiliá-los na efetivação de tais proposições no cotidiano. Para isso ocorra, as propostas de formação continuada necessitam ser coerentes com as propostas pedagógicas apontadas nos Documentos.

Para além dos problemas de coerência interna das próprias propostas curriculares (SKRSYPCSAK, 2007; PERES, 2008), algumas questões vem à tona nesta reflexão. Qual a apropriação que os docentes têm das propostas? A partir deste nível de apropriação o que tem se constituído em ação pedagógica no cotidiano dos professores? Essas questões nos levam a perguntar que ações governamentais foram realizadas para que os docentes efetivamente se apropriassem das propostas pedagógicas: que ações de formação continuada os órgãos governamentais têm propiciado aos docentes? Cientes de que os processos de formação continuada não garantem por si mesmos a qualidade à Educação, tomamos a formação continuada dos professores como elemento indispensável quando nos referimos a essa questão. Daí nos questionamos, em relação às proposições governamentais, se a formação promovida constitui-se em "formação continuada" ou é um agregado de cursos desconexos e descontínuos?

Essas questões referem-se diretamente ao debate da relação teoria e prática. Ao atuarmos com formação continuada de docentes das redes públicas de ensino é comum a manifestação de que na teoria tudo parece ser bom, que atende a necessidade e, mais do que isso, a vontade dos docentes de realizarem uma ação pedagógica não conservadora em uma formação crítica dos alunos. Mas, assinalam os professores, se por um lado as propostas atendem tal interesse, por outro no momento de por em prática a teoria se mostra insuficiente ou desconectada com a realidade cotidiana das escolas. O que se expressa nessas manifestações dos professores é uma dicotomia entre teoria e prática sem, porém, uma sustentação plausível. Quando perguntados sobre as compreensões que possuem de teoria e de prática fica evidente que não conseguem estabelecer uma significação razoavelmente coerente nem para um e nem para outro conceito. Portanto, esperar que articulem teoria como uma determinada leitura ou expressão da efetividade das ações seria uma ingenuidade.

Ao observarmos o estudo de Euzébio (2009) sobre a apropriação na formação inicial de professores de educação física, ficou-nos evidente que a prática dos professores é coerente com a predominância dos conhecimentos que são oferecidos aos mesmos em sua formação. Não há, portanto, a dicotomia teoria e prática, pois as ações pedagógicas como relatadas pelos próprios professores é realizada em consonância com a abordagem e sentido dado aos conhecimentos apropriados.

Isso nos leva a refletir sobre a realidade das escolas públicas do Ensino Fundamental, em específico da Rede Estadual de Santa Catarina, que a mais de vinte anos possui uma Proposta Curricular que estabelece as orientações, na perspectiva Histórico-Cultural. Sobre esse tema, a questão que nos orientou foi se os programas de formação continuada, se é que eles existem como tal, propiciam aos educadores a apropriação teórico-prática das orientações da Proposta Curricular de Santa Catarina? 
O desenvolvimento da prática pedagógica cotidiana dos professores estaria demonstrando que de fato "na prática a teoria é outra" ou, exatamente ao contrário, estaria demonstrando que os professores não se apropriaram das orientações pedagógicas constantes na Proposta Curricular de Santa Catarina e, portanto, "na prática a teoria é a mesma"?

Esta última questão é bastante instigante uma vez que no meio acadêmico as perspectivas denominadas críticas de educação, principalmente as que se consubstanciam na pedagogia histórico-crítica estão em forte questionamento e descrédito, uma vez que defendem a questão do conhecimento historicamente produzido como indispensável no processo de ensino.

Parte-se do entendimento de que tratar da questão da prática pedagógica pelo viés do conhecimento não é desfocar o debate pedagógico e, menos ainda, não é remetê-lo para um segundo plano. Antes ao contrário, é tomá-lo de frente, sem desvios e sem subterfúgios. Para tal é preciso que se mantenha uma permanente investigação dos discursos sobre as orientações teórico-metodológicas - especialmente as "Propostas Curriculares" de iniciativa governamental nos estados e municípios - para conferir-Ihes a coerência, a abrangência e seus possíveis desdobramentos enquanto orientadores dos debates sobre as práticas sociais, especialmente as educacionais/ pedagógicas.

Alguns autores já empreendem tal abordagem. Dessa forma podemos verificar que Duarte $(1998,2000,2003)$, em seus estudos na busca de compreender a relação dialética entre ontologia e epistemologia nos estudos educacionais, mais especificamente em relação ao trabalho educativo, denuncia o processo de psicologização que este debate sofreu no contexto educacional brasileiro. O autor enfatiza, por exemplo, como o pensamento de Vigotski é apropriado e interpretado - e poderíamos acrescentar até certo ponto deturpado - sob a perspectiva interacionista, perspectiva esta claramente díspar, por exemplo, com o que pretende ser a orientação dos Parâmetros Curriculares Nacionais.

Moraes (1996, 2003), também preocupada com as questões da articulação entre ontologia e epistemologia, evidencia que nos debates das políticas de educação e formação docente, quando dominados pelos princípios das propostas dos organismos oficiais, ocorrem redefinições dos principais conceitos envolvidos em tais políticas, como competência, destreza, consenso, sociedade civil, democracia, cidadania, edificação, solidariedade, racionalidade, verdade, conhecimento, entre outros, que acabam por inspirar as proposições para a área de educação nas ciências sociais e na filosofia. A autora aponta que o

\begin{abstract}
processo reformista se fez legitimar pela arquitetura de um forte clima de consenso na sociedade. Importantes intelectuais que atuam em departamentos de educação de organismos multilaterais, assim como em instituições educacionais nacionais, publicaram artigos de ampla circulação alardeando que tais reformas e recomendações eram as melhores - se não as únicas - alternativas para a resolução dos problemas da educação no país. (MORAES, 2003, p. 09)
\end{abstract}

Os estudos aludidos são suficientes para indicar a emergência da necessidade de debate qualificado para apresentar alternativa à perspectiva que quer nos fazer crer que a "única" saída para os problemas 
atuais, próprios da complexidade das relações sociais contemporâneas, portanto da nova condição exigida pela reorganização da sociedade baseada no modo de produção capitalista, é a atuação pragmática ou neopragmática. Acreditamos em uma educação de qualidade, mas uma qualidade estabelecida pelos interesses e necessidades dos que efetivamente realizam no cotidiano o processo de educação, professores, especialistas, gestores e comunidade. Nesse sentido a qualidade ganha outros contornos, não mais estabelecidos de forma unilateral sob orientação de organismos multilaterais, cujos interesses estão subjugados ao capital, mas uma educação de qualidade sob novo parâmetro, com a participação de todos, para uma escola com "qualidade social".

Com o objetivo de contribuir com esta perspectiva pretende-se empreender uma investigação estabelecendo diálogo entre a Proposta Curricular de Santa Catarina (SANTA CATARINA, 1991, 1998, 2005) e os Programas e Cursos de formação continuada promovidos pela Secretaria de Estado da Educação de Santa Catarina.

\section{Formação continuada na GERED de Criciúma: a continuidade da descontinuidade}

Nesse momento, iremos expor o processo de formação continuada que ocorreram no período de 2003 a 2010 na GERED de Criciúma. Nesse tempo histórico houve em todos os anos cursos que se encaixariam como formações continuada, ou seja, ocorreram cursos isolados que teriam como objetivo dar subsídios contínuos aos docentes da rede estadual.

Os cursos efetivados pela GERED ocorreram de forma fragmentada e desarticulada entre os próprios cursos, isto é, não possuem articulação nem de orientação teórico-metodológica nem de conteúdo, além de que em cada curso um grupo diferente de professores os frequentou. Com base no material pesquisado constatamos que houveram sessenta e um cursos. Destes cursos apenas três foram voltados para discutir aspectos sobre a Proposta Curricular (1991) e/ou algum documento derivado da mesma9

Destes três cursos foram debatidos: em 2004 o curso "Proposta Curricular de Santa Catarina e a prática docente", tendo como objetivo, de acordo com a GERED, capacitar os docentes das unidades escolares da GERED/Criciúma, proporcionando o aprofundamento da teoria da atividade ${ }^{10}$ e avaliação em consonância com os pressupostos teórico-metodológico da Proposta Curricular de Santa Catarina. Contudo, esse curso foi fornecido apenas para o Gerente Regional de Educação e Inovação, Diretor Regional de Ensino e docentes de apenas quatro escolas ${ }^{11}$ do total de 62 escolas estaduais que se encontram sob gerência da GERED de Criciúma; em 2005 ocorreram dois cursos - "Seminário de Educação Básica e

9 Os demais cursos abordaram temas como gestão, organização escolar e conteúdos específicos das demais áreas de conhecimento, entre outros.

10 Ressaltamos que a teoria da atividade mencionada nesse curso não tem nenhum vinculo com a Teoria da Atividade fomentada por Leontiev.

11 As escolas foram organizadas uma em cada pólo na região, totalizando quatro, que posteriormente deveriam promover o repasse para as demais escolas. 
discussão dos eixos temáticos da proposta curricular de Santa Catarina" e "Seminário de Educação e Infância: discussão dos eixos temáticos da Proposta Curricular de Santa Catarina" -, no entanto, novamente foram direcionados a professores de escolas reunidas em determinados "polos".

Direcionando a análise para a educação física apresentamos que durante todo esse período houveram cinco cursos destinados aos docentes de educação física. Em 2005 ocorreu o curso "Projeto de Tênis Júnior ${ }^{\prime \prime 2}$ destinado, então, para docentes da área de educação física. Sobre esse curso não encontramos o conteúdo pauta, relatórios, o número de docentes que participaram e a carga horária. Apenas consta nos documentos sob domínio da $21^{\text {a }}$ GERED que ocorreu esse curso. Porém, sendo oferecido pelo NETEC em intercâmbio com a Federação Catalã, tais iniciativas, via de regra, buscam desenvolver as habilidades básicas dos referidos esportes no intuito de "detectar" talentos precoces para a modalidade esportiva. Podemos inferir que seu enfoque não é o didático-pedagógico em articulação com as orientações teórico-metodológicas da Proposta Curricular que estabelece como finalidade precípua da educação física a tematização do conhecimento sócio-histórico do esporte, no caso, a modalidade de tênis, como expressão da produção histórica da manifestação da corporalidade.
O próximo curso que ocorreu com o enfoque predominantemente para a educação física foi em 2007, ofertando o curso de capacitação para docentes de educação física efetivos atuando no ensino médio, sendo o tema: "Atividade Física, Saúde e Qualidade e Vida: uma nova proposta para a educação física no ensino médio", tendo uma carga horária de cinquenta horas divididas em encontros quinzenais ocorrendo em quatro meses. O objetivo desse curso, de acordo com a GERED, foi capacitar todos os professores de educação física do ensino médio da regional de Criciúma a trabalhar com conteúdos diferenciados relacionando o exercício físico com a saúde das pessoas, além de acompanhar os professores no desenvolvimento de suas atividades.

Em 2008 ocorreu um curso muito parecido com o supracitado, intitulado: "Curso de Capacitação para Professores de Educação Física do Ensino Médio e Implantação dos Conteúdos sobre Atividade Física, Saúde e Qualidade e Vida", totalizando dez encontros de oito horas cada, disponibilizado entre os meses de março e novembro. No entanto, nesse ano esse curso foi destinado também para docentes do ensino fundamental, ocorrendo em um único encontro. O objetivo desse curso foi proporcionar uma educação física diferenciada aos alunos do ensino médio da Regional de Criciúma, estendido ao ensino fundamental, mas com

12 O projeto tênis Junior, de acordo o portal da Secretaria da Educação do estado de Santa Catarina, iniciou em 2005 em parceria entre a Secretaria de Estado da Educação e o Núcleo de Estudos de Tênis de Campo (NETEC) da Universidade Federal de Santa Catarina (UFSC), em intercâmbio com a Federação Catalã de Tênis, da Espanha. O Projeto está presente em aproximadamente 600 escolas da rede pública estadual e em nossa região, pelos dados do curso de formação, em 08 escolas. O projeto envolve além da distribuição de kits de tênis, capacitação para os professores de Educação Física. A capacitação não é uma iniciativa da Secretaria de Estado, mas como resultado do Projeto Tênis Júnior. 
foco nos conteúdos para o ensino médio. Em 2009 e 2010 ocorre o mesmo curso com o mesmo objetivo.

Podemos observar que nos diversos cursos fornecidos uma parcela muito restrita foi destinada a própria discussão sobre a Proposta Curricular de Santa Catarina (1991) e para os docentes de educação física. Dentro desses cursos voltados para a área da educação física, analisamos que os temas tratados não estavam em articulação com a Proposta Curricular. A qualidade de vida e saúde - curso com maior incidência - se articula ao movimento de saúde renovada que atualiza o paradigma da aptidão física, revitalizando a idéia de que a principal tarefa da educação física é a promoção da saúde. De base positivista e biologicista mantém a educação física como sanitarista e utilitarista o que se contrapõe à abordagem histórico-cultural. Nota-se que foi dada maior ênfase ao ensino médio, negligenciando-se os demais níveis de ensino. Ademais, mesmo que o ensino médio continue a exigir, no interior da área, a compreensão de sua especificidade, não consideramos que a temática atividade física e saúde deva ser restrita a ele. Entretanto o processo de expandir a temática para professores de outros níveis ascende à problemática da abordagem da proposta do curso estar centrada nos elementos anátomo-fisiológicos. Consideramos que a temática deve receber o tratamento de sua efetiva possibilidade dos alunos objetivarem tal prática, o que exige tomar em consideração os múltiplos determinantes envolvidos na relação atividade física e saúde, tais como, condições financeiras, tempo disponível e espaço físico para a prática, valores culturais e religiosos, entre outros. Para a Proposta Curricular quanto a educação física "os conteúdos e conhecimentos só adquirem significados, se vinculados à realidade existencial dos alunos, se estiverem voltados para resolução de problemas colocados pela prática social e forem capazes de fornecer instrumentais teórico-práticos para questioná-la." (SANTA CATARINA, 1991, p. 69)

Compreendemos que esses cursos não contribuíram para a intervenção pedagógica e para uma explicitação dos aportes que constam no interior da Proposta Curricular. Portanto, essa ação caracteriza-se como um processo "dito" de formação continuada, desarticulada, sem conexões teóricas, não tendo uma preocupação em explicitar conteúdos, metodologias que se coadunem com a Proposta Curricular, em suma, tornando-se um processo de continuidade da descontinuidade.

\section{CONSIDERAÇÕES FINAIS}

Com base nos dados acumulados e analisados podemos observar a continuidade da formação continuada para docentes que ministram aulas na rede educacional estadual na região da GERED de Criciúma de forma fragmentada, etapista e terminal. Não encontramos diretrizes ou orientações que regem as formações articuladas com a Proposta Curricular e, consequentemente, não havendo um processo que realmente alicerce os docentes em suas ações de intervenção pedagógica com a pesrpectiva histórico-cultural. Isso é destacado pela própria Proposta Curricular catarinense, quando aponta como tarefa mais significativa a de "capacitar permanentemente seus profissionais, de modo que possam apropriar-se dos conceitos referenciais da Proposta e ao mesmo tempo, articular esses 
pressupostos com as opções metodológicas mais interessantes para a atividade docente" (SANTA CATARINA, 2005, p. 12).

Podemos, também, citar outros posicionamentos com que nos deparamos ao efetivarmos a análise dos dados da pesquisa: primeiramente que houve de fato uma formação com cursos que ocorreram de forma isolada e fragmentada. Outro fator foi que, no período estudado - com reduzido número de formações -, os temas abordados não correspondem minimamente com aquilo que a Proposta Curricular aponta em seu documento, ou seja, alguns conteúdos considerados no Documento como específicos da educação física não foram debatidos na formação continuada, como por exemplo, o esporte, a dança, o jogo, a ginástica. E, esses são temas que na Proposta Curricular está exposto como "[...] temas que mais evidenciam na formação profissional e nos currículos escolares." (SANTA CATARINA, 1991, p. 69).

Dessa maneira, fica oculto quais os objetivos dessas formações, sendo que as mesmas não estão vinculadas com os aspectos presentes na Proposta Curricular, explicitando o estranhamento e distanciamento dos docentes e até mesmo dos próprios indivíduos que se encontram no interior da GERED, perante os elementos norteadores contidos na Proposta Curricular.

\section{REFERÊNCIAS}

AVILA, A. B.; ORTIGARA, V. Conhecimento, sociedade e educação de professores: crítica consistente ou conservadorismo político? Revista Perspectiva, Florianópolis, v. 25, n. 2, jul./dez. 2007. p. 289-313.

DUARTE, N. Relações entre ontologia e epistemologia e a reflexão filosófica sobre o trabalho educativo. Revista Perspectiva, Florianópolis, v. 16, n. 29, jan./jun. 1998. p. 99-116.

. Vigotski e o "aprender a aprender": crítica às apropriações neoliberais e pós-modernas da teoria vigotskiana. Campinas: Autores Associados, 2000.

. Sociedade do conhecimento ou sociedade das ilusões?. Campinas: Autores Associados, 2003.

EUZÉBIO, C. A. O conhecimento esporte nos cursos de formação inicial em educação física. Dissertação (Mestrado em Educação). Universidade do Extremo Sul Catarinense, 2009.

MORAES, M. C. M. Os pós-ismos e outras querelas ideológicas. Revista Perspectiva, Florianópolis, ano 14, n 25, jan./jun. 1996. p. 45-60.

- Iluminismos às Avessas: produção de conhecimento e políticas de formação docente. Rio de Janeiro: DP\&A, 2003.

PERES, E. S. Os conceitos sociedade, homem, educação e aprendizagem: sua dinâmica nos textos da proposta curricular de Santa Catarina. Dissertação (Mestrado em Educação) Universidade do Extremo Sul Catarinense, 2008.

SANTA CATARINA. Proposta Curricular de

Santa Catarina: uma contribuição para a escola pública do pré-escolar, $1^{\circ}$ grau, $2^{\circ}$ grau e educação de adultos, 1991.

Proposta Curricular de Santa

Catarina: educação infantil, ensino fundamental e médio (temas multidisciplinares). Florianópolis: COGEN, 1998.

Proposta Curricular de Santa Catarina: estudos temáticos. Florianópolis: COGEN, 2005.

SKRSYPCSAK, D. Proposta curricular de Santa Catarina: pressupostos teóricos 
e especificidades da Educação Física. Dissertação (Mestrado) - Universidade do Extremo Sul Catarinense, Programa de Pós-Graduação em Educação. 2007.
TRIVIÑOS, A. N. S. Introdução à pesquisa em ciências sociais: a pesquisa qualitativa em educação. 1. ed. 18. reimpr. São Paulo: Atlas, 2009.

\title{
CURRICULAR PROPOSAL OF SANTA CATARINA AND THE CONTINUOUS FORMATION IN THE CRICIÚMASC GERED: continuity of discontinuity
}

\begin{abstract}
This article has as its focus observe continuing training courses held during the years 2003 to 2010 on 21 a GERED situated in the municipality of Criciúma/SC. We set out as a point of analysis for these formations the assumptions of the Curricular Proposal of Santa Catarina, along with other documents take effect retrospectively. The methodological issue was characterised as a documentary analysis of the formations carried out. It turns out that in the analyzed period occurred "courses" that would fall into as continuing formations, however, these courses were conducted in fragmented and disjointed way between them, resulting therefore in an inefficiency of a process that actually Foundation teachers in their actions by the guiding elements contained in the proposed Curriculum.
\end{abstract}

Key-words: Curricular Proposal of Santa Catarina; Continuing Education; Education; Physical Education. 